\title{
“AS AVENTURAS DE PINÓQUIO”: POR UM ENSINO EM PERSPECTIVA TEXTUAL
}

\author{
Dennis Castanheira \\ Doutorando em Língua Portuguesa pela Universidade Federal do Rio de Janeiro (UFRJ) \\ dennisscastanheira@gmail.com
}

\section{RESUMO}

Este artigo tem como objetivo geral debater possíveis estratégias para o ensino de língua portuguesa por meio da obra As aventuras de Pinóquio: histórias de uma marionete, de Carlo Collodi. Utilizamos como base a interface texto e ensino, remetendo, ainda, a alguns postulados dos Parâmetros Curriculares Nacionais para Ensino Fundamental II a fim de fundamentarmos nossas propostas. São explorados temas como intertextualidade e tipologias textuais associados às práticas de leitura, de produção textual e de análise linguística a partir de atividades pré-textuais, textuais e pós-textuais.

Palavras-chave: Pinóquio, texto e ensino, PCN.

\section{ABSTRACT}

This article's main objective is to discuss possible strategies for the teaching of the Portuguese language using the book The Adventures of Pinocchio by Carlos Collodi. We will base our analysis on the relationship between text and teaching, as well as some evidences found in the Parâmetros Curriculares Nacionais for the Middle School. Themes as intertextuality and textual typology will be explored in relation to reading habits, textual production and linguistic analysis using pre-textual, textual and post-textual activities.

Keywords: Pinocchio, text and teaching, PCN. 


\section{Primeiras palavras}

Língua e literatura têm sido muitas vezes desassociadas em trabalhos teóricos e aplicadas à luz de distintas abordagens teórico-metodológicas. Este artigo tem como objetivo geral apresentar reflexões para o ensino de língua portuguesa no sexto ano do Ensino Fundamental a partir da obra As aventuras de Pinóquio: histórias de uma marionete, de Carlo Collodi. Para isso, serão utilizadas questões relativas à interface texto e ensino e algumas preconizações dos Parâmetros Curriculares Nacionais (PCN) de português para Ensino Fundamental II.

Metodologicamente, escolhemos a tradução feita por Marina Colasanti e publicada pela editora "Companhia das Letrinhas" por ser uma das mais populares e bem avaliadas. Além disso, buscamos estabelecer nossas sugestões para o ensino a partir de atividades pré-textuais, textuais e pós-textuais articuladas às três práticas de linguagem propostas por Geraldi (2011 [1984]) e retomadas pelos PCN: leitura, análise linguística e produção textual.

Na seção "Texto e ensino", discutimos o conceito de texto e alguns aspectos importantes para nossas sugestões de atividades: tipologias textuais e intertextualidade. Além disso, apresentamos a relação entre essa abordagem e a perspectiva de Geraldi (2011 [1984]) acerca de um ensino baseado em leitura, análise linguística e produção textual. Na seção seguinte, "Questões metodológicas", debatemos as escolhas metodológicas deste artigo, destacando a importância de trabalhar com a obra original em sala de aula. Já em “'As aventuras de Pinóquio': caracterização e sugestões de atividades", retomamos postulados anteriores sobre a obra e trazemos algumas 
sugestões para o trabalho com ela em sala. Por último, revisitamos as contribuições deste artigo e estabelecemos novos passos a serem percorridos.

\section{Texto e ensino}

Acreditamos que um dos focos centrais no ensino de língua portuguesa deva ser o texto. Consideramos não ser possível operacionalizar o trabalho pedagógico sem relacionar os usos linguísticos, seus contextos de produção e sua forma na construção dos seus sentidos. Por isso, seguimos, neste artigo, para fundamentar nossas propostas, a relação entre texto e ensino (MARQUESI; PAULIUKONIS; ELIAS, 2017). Para trabalhar o texto na sala de aula, é preciso analisar as relações nele presentes, indo além de aspectos formais, e focalizando aspectos discursivo-pragmáticos.

Essa perspectiva está relacionada ao conceito de texto, tido como o local da interação, "um evento comunicativo em que estão os elementos linguísticos, visuais e sonoros, os fatores cognitivos e vários aspectos" (CAVALCANTE, 2011, p. 20). Nessa visão, os sentidos não estão explícitos na superfície textual, havendo, apenas, marcas linguísticas que serão acrescidas aos conhecimentos compartilhados pelo leitor e a suas interpretações. Há, então, um complexo processo de coconstrução dos sentidos do texto que ocorre em perspectiva interacional e sociocognitiva.

Cada texto apresenta algumas tipologias textuais, ou seja, formas de organização do discurso. Marcuschi (2008) defende que há cinco tipologias: narração, descrição, argumentação, exposição e injunção. Definiremos as duas que trabalharemos neste artigo: narração e descrição. Enquanto a narração engloba o relato de fatos, acontecimentos e ações; a descrição compreende a caracterização e identificação de 
seres, objetos, etc. Ambas têm marcas linguísticas típicas que abordaremos posteriormente. É preciso ressaltar, ainda, que, embora haja uma divisão didática para as tipologias, um mesmo texto pode apresentar diversas tipologias ocorrendo concomitantemente.

Um aspecto importante na análise da produção de sentidos é a intertextualidade. Segundo Koch, Bentes e Cavalcante (2007), o processo de intertextualidade envolve textos relacionados a outros textos já produzidos e compartilhados pela memória social dos interlocutores, constituindo uma estratégia bastante recorrente na produção e na leitura de textos orais e escritos. Sua constituição pode ocorrer de diversas formas, dentre as quais a intertextualidade explícita, quando há citação da fonte do intertexto, como em citações ou referências, ou a intertextualidade implícita, quando não há citação expressa da fonte, como em paráfrases e ironias. Conforme apontam as autoras, esse recurso é essencial para construção dos efeitos de sentido, não constituindo apenas um meio para a identificação do texto origem, mas uma estratégia discursiva e argumentativa para fins específicos.

Defendemos que esses aspectos devem ser considerados a partir da união das três práticas de linguagem propostas por Geraldi (2011 [1984]) e retomadas pelos PCN: leitura, análise linguística e produção textual. A prática de leitura envolve a formação de leitores críticos a partir do trabalho com variados gêneros, privilegiando a efetiva compreensão textual a partir de elementos verbais e/ou não verbais. A prática de análise linguística consiste na ruptura da visão tradicional de exercícios gramaticais descontextualizados. Nessa nova concepção, o texto é a unidade de ensino central, não sendo utilizado mais como pretexto, mas como base para qualquer trabalho em sala de aula. A língua passa a ser concebida como uma ação interlocutiva fruto do contexto social 
em que se insere. A metodologia do professor baseia-se na reflexão e na preferência por questões mais abrangentes que englobam comparação e reflexão sobre os efeitos de sentido.

Já a prática de produção de textos caracteriza-se por visar a textos com diferentes características. A partir de gêneros textuais orais e escritos, considera-se o texto como um processo e não como um produto. Ou seja, o texto não é mais visto como uma unidade acabada, que contém sentidos estanques, provenientes do que está nele escrito/dito. É preciso, então, ir muito além da tessitura do texto, considerando, por exemplo, o gênero e o suporte em que ele será produzido.

\section{Questões metodológicas}

As diretrizes oficiais para Ensino Fundamental propõem que devemos tratar, em contexto pedagógico, de distintos gêneros, mas adverte que precisamos ter cuidado ao limitarmos nossa seleção textual a obras de literatura infantil. Isto é:

a visão do que seja um texto adequado ao leitor iniciante transbordou os limites da escola e influiu até na produção editorial. A possibilidade de se divertir com alguns dos textos da chamada literatura infantil ou infanto-juvenil, de se comover com eles, de fruí-los esteticamente é limitada. Por trás da boa intenção de promover a aproximação entre alunos e textos, há um equívoco de origem: tenta-se aproximar os textos simplificando-os aos alunos, no lugar de aproximar os alunos a textos de qualidade (BRASIL, 1998, p. 25).

Na verdade, não há a proibição do uso de textos voltados para o universo infantil, mas a advertência que o aluno deve conhecer, saber reconhecer e utilizar outros gêneros 
(receitas, notícias e cartas são alguns exemplos) em distintos suportes e domínios discursivos.

Assim:

assumir a tarefa de formar leitores impõe à escola a responsabilidade de organizar-se em torno de um projeto educativo comprometido com a intermediação da passagem do leitor de textos facilitados (infantis ou infanto-juvenis) para o leitor de textos de complexidade real, tal como circulam socialmente na literatura e nos jornais; do leitor de adaptações ou de fragmentos para o leitor de textos originais e integrais (BRASIL, 1998, p. 70).

Deve ocorrer, então, a passagem da leitura e interpretação de textos de caráter exclusivamente infanto-juvenis para outros ainda não conhecidos ou menos familiares ao aluno. Por isso, a escolha de sugestões de atividades para serem trabalhadas com sexto ano do Ensino Fundamental, já que essa é uma etapa transitória em que o aluno entra em um novo seguimento escolar e deve começar a discutir textos mais complexos.

As aventuras de Pinóquio: histórias de uma marionete ganha especial importância por ser uma obra que vai muito além do aspecto infantil, como outras histórias que os alunos têm conhecimento. Mesmo que versões deste conto de fadas sejam conhecidas, provavelmente, ainda não foram apresentadas as diversas especificidades do original de Collodi. A versão mais famosa, dos estúdios de Walt Disney, guarda pouquíssima semelhança com a obra na qual se baseia, o que reforça essa perspectiva.

Dessa forma, ao lerem a tradução do original, os alunos estarão, assim como propõem as diretrizes oficiais, no percurso de passagem para textos mais complexos, utilizando, uma história que eles acreditam já conhecerem. Sendo assim, esse período 
guarda um estranhamento menor, podendo, portanto, ser mais produtivo do que a ruptura total com textos que não estejam no universo infanto-juvenil.

Além de se basearem nessa obra, nossas propostas são caracterizadas: (a) pela união das práticas de linguagem: leitura, produção textual e análise linguística; (b) pela congregação de atividades pré-textuais, textuais e pós-textuais (cf. SANTOS; CUBA RICHE; TEIXEIRA, 2012), a saber:

(1) atividades pré-textuais: ligadas à motivação para leitura;

(2) atividades textuais: ligadas a questões próprias do texto;

(3) atividades pós-textuais: continuação da análise e motivações para leituras posteriores.

A partir da associação dessas etapas, visamos a trabalhar com aspectos textuais, como tipologias e intertextualidade, enfocando sempre a importância do texto na sala de aula.

\section{3. "As aventuras de Pinóquio": caracterização e sugestões de atividades}

É preciso que, antes de debatermos estratégias para o trabalho com "As aventuras de Pinóquio" em sala, compreendamos sua caracterização. A obra foi escrita por Carlo Collodi, ilustrada por Enrico Mazzanti e publicada, na Itália, capítulo a capítulo em forma de folhetim no século XIX. O livro narra as aventuras de Pinóquio, boneco de madeira que sonha em ser "um menino de verdade". A obra tem incontáveis versões que, mesmo com suas especificidades e suavizações para determinado público-alvo, buscam narrar as aventuras do boneco e seu encontro com personagens, como o Grilo falante e a Fada de cabelos turquesa. 
Diferentemente de adaptações posteriores, nem Gepeto, nem Pinóquio eram tão bondosos ou inocentes na primeira versão. O boneco, criado a partir de um pedaço de madeira mágico, era bastante impulsivo, rebelde e mal-educado; Gepeto, por sua vez, tinha em Pinóquio a esperança de obter ganhos financeiros. Ao longo da narrativa, contudo, o velho homem tenta inúmeras vezes ajudar o boneco, sacrificando-se ao extremo e passando fome e frio. Com um comportamento constantemente egoísta, Pinóquio redime-se ao fim da obra, cuidando de Gepeto e da Fada de cabelos turquesa, aqueles que mais o ajudaram e lutaram para que seguisse um caminho menos pesaroso.

Corso e Corso (2006) discutem algumas características da obra original de Pinóquio e defendem que a primeira versão apresenta aspectos mistos de contos de fadas e fábulas. Se, por um lado, não pode ser tida como um conto de fadas prototípico como “A Bela e a Fera" e "A Bela Adormecida", por outro, a obra se distancia das fábulas ao ter um herói que sempre é perdoado e que tem a necessidade de mostrar que não entendeu a lição passada. Corso e Corso (2006) defendem que, na verdade, a história envolve uma "antifábula". Neste artigo, focalizaremos especificamente algumas características da obra que podem colocá-la próxima aos contos de fadas.

Segundo Oliveira (2010), os contos de fadas tiveram sua origem como mito primitivo, passando a uma leitura poética céltica e, posteriormente, a histórias violentas na Idade Média. Apenas no século XIX, eles ganharam um caráter fantasioso e lúdico, como conhecemos atualmente. Servindo de inspiração para diversos longas-metragens infantis, sobretudo dos estúdios Disney, tornaram-se cada vez mais populares, principalmente com o público infanto-juvenil.

Santos e Cuba Riche (2016, p. 138) apontam que, 
por serem histórias que encantam leitores há séculos, os contos de fadas têm sido recontados e sofrido as mais diversas alterações ao longo do tempo. Chama a atenção, porém, a quantidade de paródias desses contos, ora mesclando personagens originais com os de outras histórias, ora inserindo um elemento inovador, ou ainda recontando a narrativa sob a perspectiva de um dos personagens secundários.

Os contos de fadas apresentam características típicas, como a existência de seres mágicos, o processo de autodescoberta do herói, além de tempo e espaço não necessariamente determinados. Oliveira (2010) ressalta, ainda, que eles envolvem forte caráter simbólico, podendo ser relacionados ao universo fantasioso da criança por meio de uma linguagem eminentemente metafórica a partir de elementos verbais e não verbais.

A importância de trabalhar os contos de fadas é grande e vai muito além do que atestam os PCN.

Especialistas afirmam que a tendência de retirar o mal, o medo e o castigo das narrativas são fortes atualmente. As mudanças de enredo apazíguam as emoções que precisam ser vividas. Não é saudável evitar que as crianças enfrentem os conflitos assim, é possível usar e abusar de filmes que recontam A Bela e a Fera e $\mathrm{O}$ Patinho Feio, por exemplo, mas é preciso apresentar primeiro as obras que mais se aproximam dos originais (OLIVEIRA, 2010, p. 38).

Trabalhar em sala de aula com as histórias originais, então, é uma tarefa bastante relevante. Diferentes atividades podem ser elaboradas para que sejam apresentadas tais versões aos alunos. Temos que atentar, primeiramente, contudo, para o conhecimento prévio da turma. A maior parte dos estudantes já conhece alguma versão dos contos de fadas mais famosos, inclusive Pinóquio. Quais estratégias, então, devemos adotar? 
O primeiro aspecto a ser considerado em perspectiva pré-textual é a divergência de enredos, personagens, ilustrações e outros recursos semióticos que constroem o texto e, consequentemente, seus sentidos. Como atividade, sugerimos, primeiramente, a comparação das versões que os alunos conhecem do conto de fadas trabalhado. É preciso destacar semelhanças e diferenças.

Uma alternativa é, antes de trabalhar com a obra original, pedir aos alunos que produzam textos escritos sobre a história de Pinóquio, tentando manter, ao máximo, a semelhança com a aventura vivida que está na memória de cada um. Após a leitura da obra, essa atividade é retomada, como discutiremos posteriormente.

Ainda para execução da comparação de versões, o professor pode adotar, após a leitura do original, ao menos, duas estratégias. Uma possibilidade é promover um debate com a turma, observando, de forma geral, quais as diferenças entre as versões. São questionamentos possíveis: "quais os personagens da história?"; "sua representação ocorre de forma semelhante?". Pode ser ressaltada a personagem Fada Azul, que, embora desempenhe papel central na obra, é representada de formas distintas na história.

Uma alternativa é recolher os livros que os alunos tenham, em casa, do conto de fadas que será estudado. Na aula anterior, o professor pode pedir que cada um leve o que tem relacionado a Pinóquio. O professor também deve adotar uma metodologia comparativa a partir do que os alunos levarem para que sejam estabelecidas semelhanças e diferenças. Dentre outros aspectos, pode-se destacar que Pinóquio é bem mais verossímil à sua natureza "de madeira" no livro de Collodi do que em algumas adaptações, sobretudo a mais popular, dos estúdios de Walt Disney. 
No entanto, não nos devemos ater apenas a representação dos personagens. É preciso trabalhar outros aspectos para adentrarmos efetivamente na história narrada no conto de fadas. Na adaptação da Disney, "Pinóquio" apresenta sutis diferenças em relação a versões de outros estúdios de animação. O professor deve questionar se isso é relevante. Para execução dessa atividade, os alunos devem assistir a mais de uma versão para observarem se essa representação está ligada a outros aspectos da história ou se é apenas uma mudança pouco motivada de sua representação.

Após comparar as versões compartilhadas na turma, pode ser estabelecido outro questionamento: por que há diferentes versões para a mesma história? É a partir desse ponto que o professor trabalhará mais profundamente características dos contos de fadas com os alunos. É importante que eles já tenham participado da primeira atividade para que percebam que a existência de versões distintas não é arbitrária.

Para relacionar a obra trabalhada com outros contos de fadas, o professor pode indagar-Ihes diretamente a semelhança dessa característica com outras histórias. Ao trabalhar "Pinóquio", o professor pode perguntar se "Cinderela" e "A Bela Adormecida" também apresentam outras versões e vice-versa. Ele pode, ainda, levar ilustrações dessas obras que demonstrem a existência de variantes para que isso fique mais claro para os alunos.

Após a turma observar que diversos contos de fadas têm versões diferentes, o professor deve ressaltar a tradição oral envolvida nesses textos, sobretudo por sua origem milenar. Com a ausência de escrita ou a dificuldade em seu acesso pela maior parte da população, era comum que as histórias fossem transmitidas prioritariamente de forma oral ao longo de anos, de geração em geração. 
Dessa forma, é natural que a maior parte dos contos de fadas não tenha uma autoria definida. Os alunos provavelmente não sabem quem criou a obra ou a creditam aos estúdios Disney, devido a sua grande repercussão. Em casos como Branca de neve $e$ os sete anões não há um autor definido, embora a versão dos irmãos Grimm seja até hoje a mais famosa e a que vem se consolidando como "verdadeira", sobretudo por quem desconhece as características dessas histórias.

O professor deve explicar, por meio de exemplificação clara, as origens dos contos de fadas, ressaltando a mudança em sua constituição e em seus objetivos comunicativos. Ao ter como foco, atualmente, o público infanto-juvenil, não há como serem mantidas características semelhantes a suas versões mais sombrias da Idade Média, por exemplo.

O professor deve enfocar que a existência de qualquer texto oral ou escrito só ocorre devido a fins comunicativos específicos, tendo em vista que cada texto está inserido numa determinada época e é utilizado pelos usuários da língua em contextos reais. Além disso, ultrapassará uma abordagem meramente estrutural ou esquemática acerca do texto, sem utilizá-lo como um mero pretexto ou um produto acabado do ato comunicativo.

Em relação às atividades textuais de leitura, o professor pode desenvolver a descrição dos personagens, ressaltando suas características e seus comportamentos. Os alunos já teriam, provavelmente, levantado hipóteses e comparado versões nas atividades pré-textuais, mas, nesse momento, é importante que o professor se preocupe, inicialmente, com a descrição do que realmente ocorre com os personagens no livro.

A prática de análise linguística deve ser trabalhada a partir de aspectos que relacionem os contos de fadas com as tipologias textuais neles presentes por meio de atividades textuais em que sejam enfocados os efeitos de sentido dos elementos 
linguísticos no texto. Por meio da reflexão linguística, podem ser abordados elementos recorrentes na obra estudada para que, posteriormente, haja uma sistematização. 0 professor pode trabalhar as tipologias textuais - narração e descrição - e a relevância de algumas marcas linguísticas nelas presentes: verbos no pretérito e no presente, adjetivos e advérbios. É preciso que o aluno consiga perceber, de alguma forma, que adjetivos e alguns grupos de advérbios são essenciais para caracterização dos personagens, do tempo e do espaço.

Uma sugestão de trecho é: “De fato, um agarrou Pinóquio pela ponta do nariz, o outro agarrou pelo queixo, e começaram a puxar sem a menor cerimônia, um para cá e o outro para lá, para obrigá-lo a escancarar a boca. Mas não houve jeito. A boca da marionete parecia pregada e rebitada" (COLLODI, 2002, p. 59), em que o narrador usa as expressões verbais "começaram a puxar", "agarrou" e "houve" que estão no passado, recurso muito usado quando contamos uma história. Além disso, utiliza também os adjetivos "pregada" e "rebitada" que colaboram para a descrição da boca de Pinóquio e, consequentemente, para a narrativa apresentada.

Também é importante que o professor trabalhe o reconhecimento da estrutura do texto, ressaltando, por exemplo, a formatação de parágrafos e outros recursos usados. Assim, os alunos perceberão a organização textual da obra, o que engloba aspectos verbais e não verbais. Além disso, o professor deve fazer referência ao uso da pontuação: travessões e dois pontos são recursos sintáticos típicos da tipologia textual narrativa. Podem ser trabalhados trechos, como: "- Marionete marota! Como percebeu que era eu? / - Quem me contou foi o bem enorme que Ihe quero" (COLLODI, 2002, p. 107), ressaltando sua importância para os objetivos comunicativos dos contos de fadas. Assim, evitamos que ocorra "o ensino descontextualizado da metalinguagem, normalmente 
associado a exercícios mecânicos de identificação de fragmentos linguísticos em frases soltas" (BRASIL, 1998, p. 18).

Após executar atividades pré-textuais e textuais, o docente deve prosseguir seu planejamento com atividades pós-textuais. É retomada, nesse momento, a atividade inicial proposta nesta seção. O professor deve retomar as histórias escritas pelos alunos antes da leitura do livro, usando, inclusive, projeções das produções e quadros resumitivos/comparativos.

Logo após, o professor pode dividir a turma em pequenos grupos para que cada um exponha, preferencialmente de forma oral, uma comparação entre as versões que tiveram acesso. Podem ser abordados aspectos relacionados à organização textual (recursos estilísticos, linguísticos), à estrutura (quantidade de capítulos) e à caracterização dos personagens. Para efetuar essa proposição, é importante que tenham sido feitas as atividades que propusemos acerca da comparação das versões, pois os alunos já terão, ao longo de todo o percurso, construído algumas reflexões que certamente ecoarão nessa atividade.

Ainda como atividade pós-textual, o professor pode trabalhar a intertextualidade. Primeiramente, é preciso fazer as seguintes indagações: "vocês lembram-se do personagem Pinóquio em outro livro?"; "e em algum filme?"; "e em alguma história em quadrinhos?". Nessa etapa, o professor pode utilizar, por exemplo, os filmes "Shrek" e "A.I. - Inteligência Artificial" e algumas histórias em quadrinhos da "Turma da Mônica".

$\mathrm{Na}$ franquia de filmes "Shrek", Pinóquio é um personagem bastante ativo, coexistindo com outras figuras de contos de fadas, como Cinderela, Branca de Neve e Bela Adormecida. Com características que mantêm apenas o essencial do original (crescer o nariz quando conta alguma mentira e ser de madeira), a nova versão do boneco ganha 
comportamento próprio e interage com personagens que não têm ligação com sua história de origem.

Já no filme "A.I. - Inteligência artificial", as referências vêm por meio do menino Henri, um robô criado para agir como humano, que, após ouvir a história de Pinóquio, acredita que, caso encontre a fada azul, se tornará um menino real, assim como o boneco de madeira. É nessa referência que todo o filme está baseado, representando uma incessante busca pelo "ser de verdade".

Em "Turma da Mônica”, pode ser destacado o seguinte quadrinho:

Figura 1 - Tira da turma da Mônica

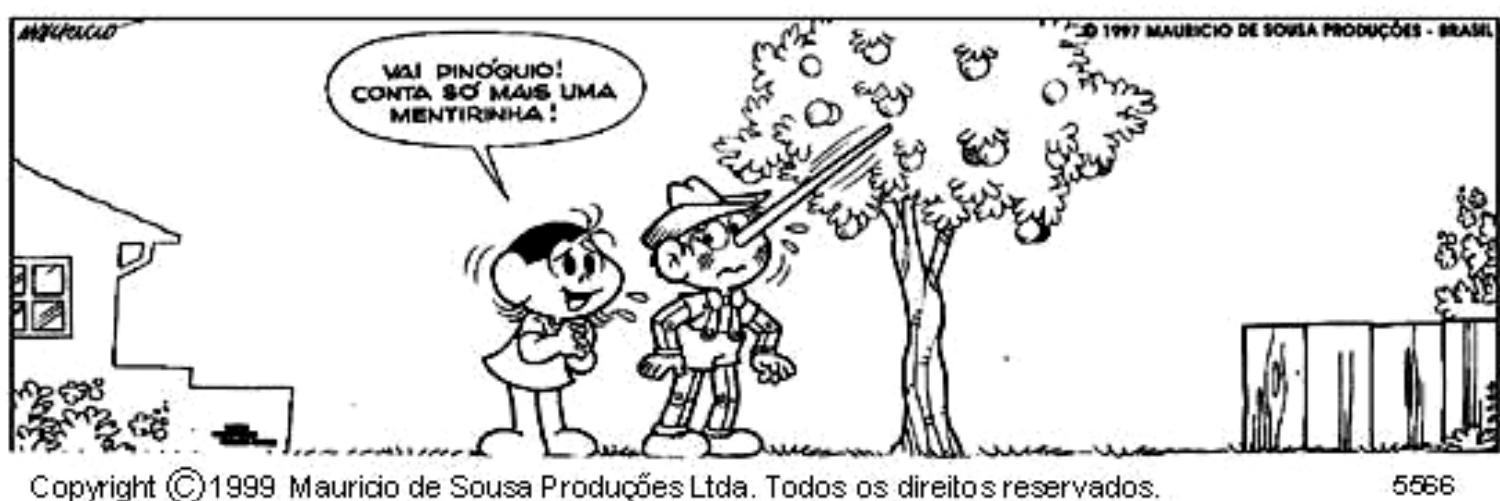

Fonte: Disponível em <http://portaldoprofessor.mec.gov.br/fichaTecnicaAula.html?aula=8697>. Acesso em: 20 abr. 2016.

Após apresentação do(s) filme(s) e/ou da(s) história(s) em quadrinhos, o professor pode debater com os alunos a relevância de Pinóquio e, principalmente, de suas características - como crescer o nariz - para as histórias de Shrek e Magali, ressaltando sua interação com os demais personagens, como Fiona, Biscoito, Lobo Mau e Magali.

Em relação ao filme "A.I.", o professor deve ressaltar a importância da metáfora de Pinóquio como fio condutor de todo o longa-metragem. Em todos os casos, é preciso que 
- leitor tenha determinados conhecimentos prévios para que possa entender, por exemplo, que, ao Pinóquio mentir, o nariz cresce. Assim, temos um exemplo concreto de trabalho com intertextualidade em sala.

Ainda sob viés pós-textual, o professor pode pedir aos alunos que desenvolvam ilustrações passíveis de serem incluídas na versão de Collodi, o que pode ser feito a partir de desenhos à mão livre, a partir de imagens criadas por programas computadorizados e/ou aplicativos de celular ou com recortes de revistas que montem, por exemplo, possíveis cenários e personagens não retratados visualmente. Sendo assim, haverá, como recomendam os PCN, o estabelecimento "das relações necessárias entre o texto e outros textos e recursos de natureza suplementar que o acompanham (gráficos, tabelas, desenhos, fotos, boxes) no processo de compreensão e interpretação do texto" (BRASIL, 1998, p. 56).

É uma possibilidade, ainda, a confecção de uma nova versão de "Pinóquio", que pode ser feita por toda a turma ou em grupos menores para uma possível exposição posterior na própria escola para outras turmas ou por meio de uma encenação teatral. Podem ser modificados o desfecho, momentos específicos (e previamente combinados) ou toda a trama, numa adaptação livre e menos comprometida com o original. Pode ser feita, inclusive, uma versão de Pinóquio nos dias atuais. Dessa forma:

diferentes linguagens verbal, musical, matemática, gráfica, plástica e corporal como meio para produzir, expressar e comunicar suas ideias, interpretar e usufruir das produções culturais, em contextos públicos e privados, atendendo a diferentes intenções e situações de comunicação (BRASIL, 1998, p. 7-8). 
Ainda, na busca pela elaboração de atividades pós-textuais, sugerimos uma atividade final que retome, na medida do possível, o que foi debatido a partir de uma comparação entre as diferentes versões, inclusive a(s) produzida(s) pelos alunos. 0 professor pode fazer perguntas, como: "qual a semelhança entre os originais, ou as primeiras versões conhecidas, e as histórias hoje contadas?" Esse debate é extremamente importante, pois ressaltará a trajetória de construção dos contos de fadas social e historicamente.

A partir dessa atividade pós-textual, efetuaremos o início de uma nova proposta pré-textual, voltada para outros contos de fadas. Isto é, estabeleceremos um ciclo em que uma sequência de atividades está inserida num contexto mais amplo, ligado a outras obras, inclusive. Após "Pinóquio", podem ser trabalhadas outras histórias, como: "Cinderela" ou "A Bela e a Fera". Assim, não devemos encarar as propostas formuladas para o ensino como um trabalho isolado, mas como uma constante na prática pedagógica, procurando ligar os tópicos gramaticais e textuais dos conteúdos programáticos, integrando-os para um ensino mais reflexivo e produtivo.

\section{Considerações finais}

Diante da associação das preconizações dos PCN com alguns aspectos da relação texto e ensino, buscamos, neste artigo, elaborar algumas sugestões de atividades prétextuais, textuais e pós-textuais que envolvam a associação das práticas de leitura, de produção de textos e de análise linguística a partir da obra As aventuras de Pinóquio: histórias de uma marionete, considerando seu caráter fantástico, conectado com o universo dos contos de fadas. 
Apontamos como possíveis próximos passos: (I) o trabalho com outros contos de fadas, seguindo alguns dos caminhos já propostos em relação a Pinóquio; (II) a elaboração de sugestões de atividades considerando o aspecto de "antifábula" da obra; (III) o enfoque maior em aspectos literários (GUELFI, 1996); (IV) a focalização de fenômenos específicos como a intertextualidade (CASTANHEIRA, 2016); (V) a aplicação das atividades sugeridas em uma turma de sexto ano; (VI) a reelaboração das atividades a partir da aplicação em sala de aula.

\section{Referências}

\section{A. Bibliografia ficcional}

COLLODI, Carlo. As aventuras de Pinóquio: histórias de uma marionete. Traduzido por Marina Colasanti. São Paulo: Companhia das Letrinhas, 2002.

\section{B. Bibliografia teórica}

BRASIL. Parâmetros Curriculares Nacionais - terceiro e quarto ciclos do ensino fundamental: língua portuguesa. Brasília, Secretaria de Educação Fundamental MEC, 1998.

CASTANHEIRA, Dennis. Intertextualidade e ensino: "Pinóquio", "Turma da Mônica" e "Shrek". In: BITTECOURT, R. L; CAMERINI, N. C. (Orgs.). Formação de professores em debate. Cabo Frio, RJ: Dictio Brasil, 2016, v. 3, p. 73-92.

CAVALCANTE, Mônica. Os sentidos do texto. São Paulo: Contexto, 2011. CORSO, Diana; CORSO, Mário. Fadas no divã: psicanálise nas histórias infantis. Porto Alegre: Artmed, 2006.

GERALDI, João Wanderley. O texto na sala de aula. 5 ed. São Paulo: Ática, 2011 [1984]. 
GUELFI, Maria Lúcia Fernandes. Literatura Infantil: fantasia que constrói realidades. Revista Educação e Filosofia, 10 (20), jul.-dez. 1996, p. 131-154.

KOCH, Ingedore G. Villaça; BENTES, Anna Christina; CAVALCANTE, Mônica Magalhães. Intertextualidade: diálogos possíveis. São Paulo: Cortez, 2007.

MARCUSCHI, Luiz Antônio. Produção textual, análise de gêneros e compreensão. São Paulo: Parábola Editorial, 2008.

MARQUESI, Sueli Cristina; PAULIUKONIS, Aparecida Lino; ELIAS, Vanda Maria. Linguística textual e ensino. São Paulo: Contexto, 2017.

OLIVEIRA, Patrícia. A contribuição dos contos de fadas no processo de aprendizagem das crianças. 2010. 62 f. Monografia (Graduação em Pedagogia) - Universidade do Estado da Bahia - UNEB, Bahia. 2010.

SANTOS, Leonor Werneck dos; CUBA RICHE, Rosa. Paródia de conto de fadas. SEDA Revista de Letras da Rural/RJ, Seropédica/RJ, v. 1, n. 2, maio/ago., 137-151, 2016. ; TEIXEIRA, Claudia de Souza. Análise e produção de textos. São Paulo:

Contexto, 2012.

Recebido em 16 de janeiro de 2018.

Aceito em 23 de abril de 2018. 